\title{
THE ERUPTION AND GROWTH OF TEETH IN THE TASMANIAN DEVIL, SARCOPHILUS HARRISII (MARSUPIALIA: DASYURIDAE).
}

by Eric R. Guiler and R.W.L. Heddle

Departments of Zoology and Anatomy, University of Tasmania, Hobart.

(with one text figure and one plate)

\section{ABSTRACT}

The sequence of tooth eruption in Sarcophizus harrisiz was found to follow an anterior-posterior sequence with two exceptions. The first incisors of the upper jaw did not erupt until the cessation of suckling at about 200 days and the canines did not appear until after the commencement of molar eruption.

Although considerable variation exists in the time and sequence of eruption of the teeth, the age of the young can be determined using shank length and weight in combination with the status of the teeth.

\section{INTRODUCTION}

The homologies of the teeth of the Marsupialia were first described by Flower (1867) who showed that only one tooth, which corresponded to the last premolar of the Eutheria, was preceded by a deciduous tooth. Further, he found that this feature was homologous throughout the Marsupialia.

Thomas (1887) in a detailed study of the teeth of the Dasyuridae noted that the dental formula of Sarcophizus was $\frac{4}{3}: \frac{1}{1}: \frac{2}{2}: \frac{4}{4}: \mathrm{s}$ and showed that the two premolar teeth which disappeared from the complete succession were P2 and P4. He reported that the first incisor, which in the adult is the largest incisor tooth, is slow to develop relative to the other incisors and postulated that they represent the stage at which the Metatheria and Eutheria diverged and the teeth were "preparing themselves" for the assumption of milk dentition. This view was not accepted by Wilson \& Hill (1897), Tims (1902) or Bensley (1903).

Little further attention has been paid to the teeth of the Dasyuridae but the dentition of the Phalangeroidea, particularly the Macropodidae, has been the subject of much recent detailed examination. It has been shown that the molar eruption sequence of the larger species of kangaroos takes place over a period of years and, further, the molars progress anteriorly with age (Sharman et al, 1964). The stages of molar eruption and progression have been used as an aid to determining the age of individual animals by Shield (1958), Sadleir (1961) and Ealey (1962).

The present study was undertaken to determine the succession of events in tooth eruption in relation to age in the late pouch young and early juveniles of the Tasmanian devil, a carnivorous marsupial.

\section{MATERIALS AND METHODS}

Four pouch young, two of each sex and all litter mates, were selected for the st.udy. The age of the animals was determined from criteria established earlier (Guiler 1970) and is given in days after birth. At the commencement of the study the young had to be forcibly removed from the nipple although they were fully furred at the time. Examinations were conducted at about weekly intervals from 144 days of age until 230 days by which time the young were difficult to handle and the operation became hazardous. The 
young were also weighed and the shank measurements were taken. The growth rate of the teeth was determined from curves constructed from measurement data.

The degree of eruption of the teeth is indicated following the conventions adopted by Sharman et al (1964), namely Stage 1 - tooth just below the surface; Stage 2 - just erupting; Stage 3 - erupted, molars with all cusps just through the gum; Stage 4 fully erupted.

The sequence of events and the measurements given are the average obtained for the four animals. No difference could be established in the rate of development of the teeth in the two sexes. One animal was about 10 days late in development and weight although born at the same time. This individual was a female melanic.

\section{RESULTS}

The age at which the teeth erupt is shown in fig. 1, which also shows the length of shank and the weight of the animal. The first teeth to appear are the $I_{2}$, followed by the $I^{2}$. These are first seen at Stage 1 at 135 days but do not erupt until 144 days of age. In general, the incisor teeth are the first to erupt and, with the exception of $\mathrm{I}^{4}$, the incisor eruption is completed before the Stage 2 of the premolars which in turn precede the molars. The canine teeth appear before the completion of the molar sequence but usually after the appearance of $M 1$ in both jaws.

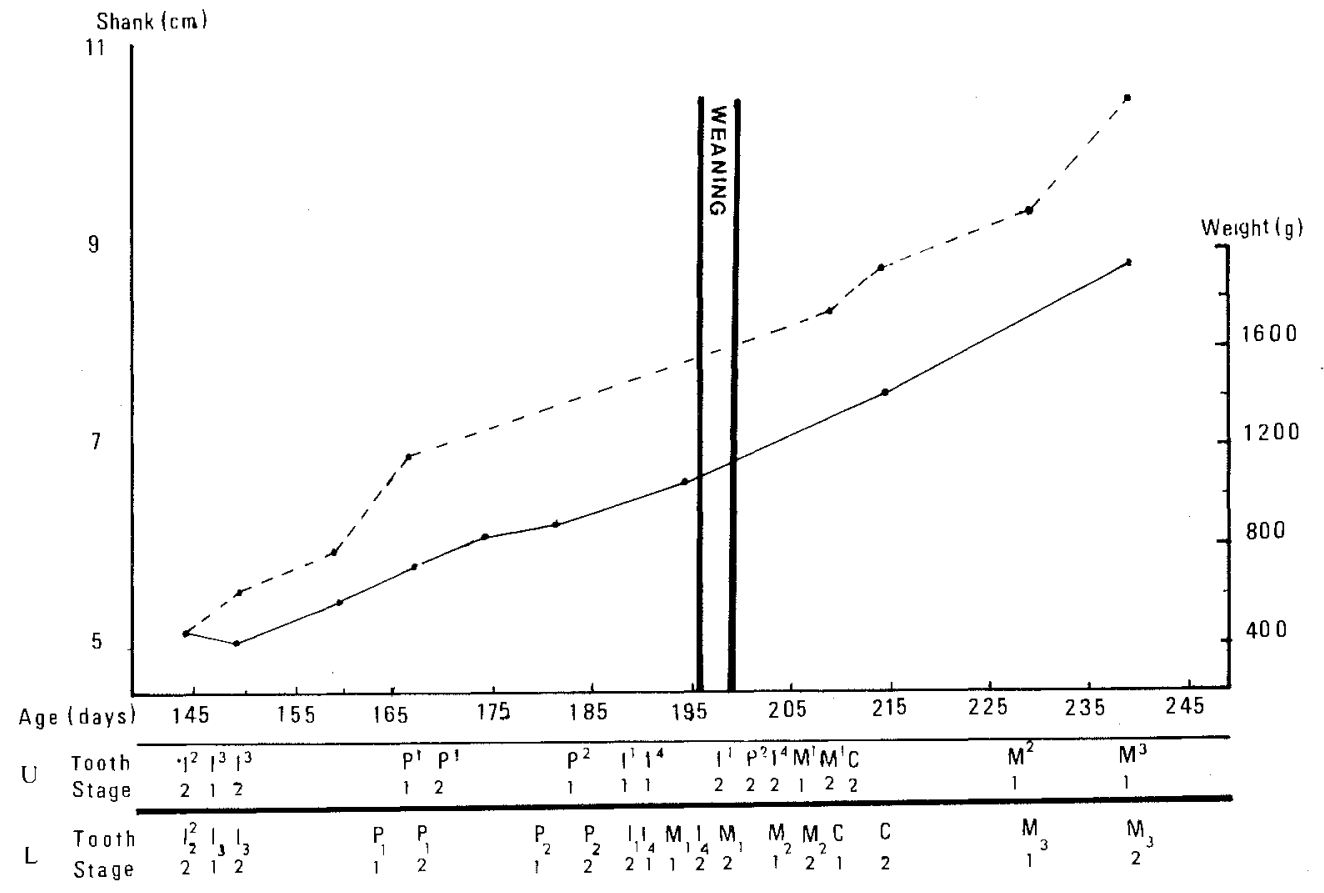

FIG. 1. - Sequence of eruption of the teeth in Sarcophizus harrisii in relation to weight, shank length and age. The lower curve shows the weight.

The $I^{1}$ do not appear as part of the normal front to rear eruption sequence of the incisor teeth, appearing later than $I^{2}$ and $I^{3}$, although the $I_{1}$ of the lower series follows very shortly after the appearance of $\mathrm{I}_{3}$. The I4 series of both $\mathrm{j}$ aws is the last of the 
pre-canine teeth to appear. The result of the late eruption of $I^{1}$ is that a gap is left in the upper incisor teeth at the antero-median part of the mouth.

The premolar and molar series follow in sequence, the canines appearing about the time of eruption of the last premolar and the first molar.

All of the $I$ and $C$ teeth appear first as conical pegs and do not assume their adult form for some 10-20 days. The $P$ and $M$ series appear in their adult tricusped condition, the anterior cusp being the first to erupt.

Considerable variation was found in the ages at which the teeth erupted in different individuals and the sequence of events changed from animal to animal. For example, the canine teeth may appear either before or after the eruption of the first molars.

The appearance of the various elements in the lower jaw usually preceded the eruption of their upper jaw counterparts by about five to seven days with the exception of 1 which does not erupt until 40 days after $I^{3}$.

\section{ERUPTION RATE OF THE TEETH}

The eruption rate of the incisor teeth was about $0.05 \mathrm{~cm}$ every 20 days until the teeth reached normal juvenile size, though as with the eruption sequence there was considerable individual variation. The $\mathrm{I}^{1}$ whenever they appeared did not grow at a more rapid rate than their predecessors. The eruption rate curve of the premolars was found to be the same as that of the incisors. Insufficient data was available to construct a growth curve for all the molars.

The eruption of the canine teeth of both jaws proceeds more rapidly than any of the other series, the rate being about $0.45 \mathrm{~cm} / 20$ days.

\section{DISCUSSION}

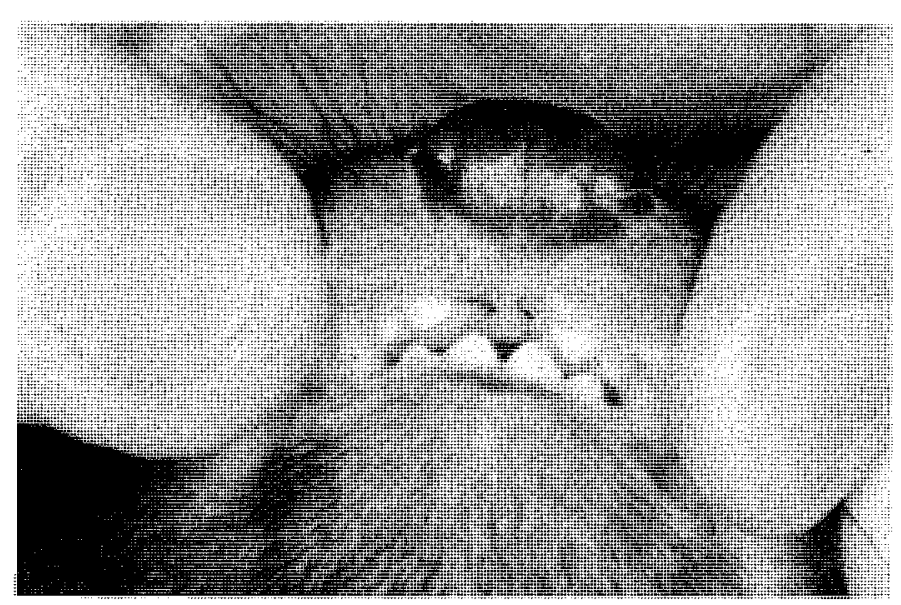

PLATE 1. - Juvenile Sarcophilus harrisii, aged $166 \pm 3$ days, showing $I_{1}$ and $I_{2}$ also $I^{2}$ and $I^{3}$ with the gap soon to be occupied by $\mathrm{I}^{1}$.
Young devils of the age of those described in this paper are not commonly available from zoological collections and have not been trapped in the wild during a seven year field study so that it hitherto has not been possible to establish some criteria for their age determination. The sequence of tooth eruption as described above together with the shank length and weight of the animal give a method of ageing devils for about 140 days after they become fully furred.

No evidence was seen of deciduous teeth such as occurs in some marsupials (Tate 1951), nor is there any evidence of a molar progression such as occurs in some adult macropods

The slow development of the $\mathrm{I}^{1}$ of each side leaves a gap between the $\mathrm{I}^{2}$ teeth. It was observed that when the nipple is being held by the young it passes through this gap. The young were kept under observation and found to be weaned by $200 \pm 5$ days, the age at which $I^{1}$ erupted and $I^{4}$ also appeared. The teats of the mother regressed and the mammary 
gland apparently ceased lactation by $208 \pm 5$ days. Thus the eruption of $\mathrm{I}^{1}$ is closely related to weaning and the evolutionary function assigned to the incisor gap by Thomas (1887) is untenable.

Field observations have shown that female devils captured in late November are not lactating and do not have any young keeping company with them. Thus, at this time, young devils must leave their mother and fend for themselves, being well equipped for this with a full set of incisors, canines, premolars and the first three pairs of molars. The food of these young devils is not known but it has been found that they are not attracted to traps containing meat bait and it would appear as if their feeding habits are somewhat different from those of the adult animal.

The amount of variation of eruption of the teeth between and within individuals makes this method of ageing unsuitable by itself for accurate age determination but when taken together with shank length and weight it offers a means of ageing young animals during their early independent life.

A drop in weight occurred in all four animals at about 150 days and may be associated with the onset of weaning, although completion of weaning was not noted until 45-50 days later.

\section{REFERENCES}

Bensley, B.A., 1903: On the evolution of the Australian Marsupialia with remarks on the relationships of the marsupials in general. Trans. Linn. Soc. Lomd. Zool., (2), $\underline{9}, 83-217$.

Ealey, E.H.M., 1962: The biology of the Euro. Ph.D. thesis, Western Australia. (Unpublished).

Flower, W.H., 1867: On the development and succession of the teeth in the Marsupialia. Phil. Trans. Roy. Soc. B., 631-42.

Guiler, E.R., 1970: Observations on the Tasmanian devil, Sareophizus harrisii, (Dasyuridae: Marsupialia). 2. Reproduction, breeding and growth of pouch young. Aust. J. Zool., 18, 63-70.

Sadleir, R.M.F.S., 1961: Fertility studies of macropods with special reference to the Euro, Macropus robustus Gould, and the marloo, M. rufus Desmarest, in the dry north west of Western Australia. Ph.D. thesis, Western Australia. (Unpublished).

Sharman, G.B., Frith, H. E Calaby, J. 1964: Growth of the poucn young, coucr eruption and age determination in the red kangaroo, Megaleia mufa. C.S.I.R.O. WizdZ. Res., 2 , 20-49.

Shield, J.W., 1958: Aspects of the field ecology of the quokka, Setonix brachyurus Quoy \& Gaimard. Ph.D. thesis, Western Australia. (Unpublished).

Tate, G.H.H., 1951: An example of prelacteal incisors in advanced pouch young of Macropus. J. Mommal., 28, 399-400.

Thomas, 0., 1887: On the homologies and succession of the teeth in the Dasyuridae, with an attempt to trace the history of the evolution of the Mammalian teeth in genera1. Phil. Trans. Roy. Soc. B., 128, 443-62.

Tims, H.W.M., 1902: On the succession and homologies of the molar and premolar teeth in the Mammalia. J. Anat. Physiol., 36, 321-43.

Wi1son, J.J. G Hi11, J.P., 1897: Observations upon the development and succession of the teeth in Peramelés. Quart. J. Micr. Sei., 39, 427-588. 